\title{
Educational Program to Enhance Pregnant Women's Knowledge about Dental Care and Periodontitis Outcomes
}

\author{
Walaa Fathy Mohamed ${ }^{1}$, Hanan Elzeblawy Hassan ${ }^{2 *}$ \\ ${ }^{1}$ Department of Maternity and Gynecological Nursing, Faculty of Nursing, Ain Shams University, Egypt \\ ${ }^{2}$ Department of Maternal and Newborn Health Nursing, Faculty of Nursing, Beni-Suef University, Egypt \\ *Corresponding Author: Hanan Elzeblawy Hassan, Maternal and Newborn Health Nursing, Faculty of \\ Nursing, Beni-Suef University, Egypt. Email: nona_nano_1712@yahoo.com
}

\begin{abstract}
Background: Gingivitis, if untreated, it will progress and cause periodontitis that causes destruction of periodontal ligaments and bone affecting about $30.0 \%$ of pregnant women causing tooth mobility and loss.

Aim of the study: The aim of the study was to enhance pregnant women's knowledge about dental care and periodontitis outcomes.

Subjects and Methods: This was an interventional study which was conducted among 300 fulfilled criteria pregnant women attending the antenatal care unit in Ain Shams Maternity University Hospital, Cairo. Data collection tools were a 'Structured Interviewing questionnaire and written Arabic booklet about periodontitis and dental care.

Result: The present study showed that the majority of the participant women had a poor knowledge level about periodontitis. Meanwhile, there was a statistically significant difference of the pregnant women's knowledge about the dental care and periodontitis outcomes after the educational session and at follow up time compared to their knowledge before it (P-value $<0.001)$.

Conclusion: Designing and implementing an educational program about the studied subject indicated a significant effect in a remarkable rising of the participants' level of knowledge about it.

Recommendations: Activating the role of the maternity health nurse in branches of obstetrics and antenatal clinics to enhance pregnant women's knowledge \& attitude regarding oral health risks during pregnancy to ensure early disease detection and adverse outcomes prevention.
\end{abstract}

Keywords: Pregnancy, periodontitis, outcomes, dental care.

\section{INTRODUCTION}

Pregnancy is a unique period during a woman's life and is characterized by complex physiological changes, which may adversely affect oral health. The development of periodontal diseases can be influenced by several factors such as human immunodeficiency virus infection, lack of dental care, poor oral hygiene, smoking, low-educational level, low-employment status, increased age, and ethnicity. These contribute to worsened periodontal condition during pregnancy. So the identification of the risk factors for periodontitis during pregnancy can help guide and establish early treatment, which can lead to the avoidance of the possible adverse effects of this disease on pregnancy. [1-3]

During pregnancy, progesterone levels increase 10-folds and estrogen levels 30-folds compared to those observed on the menstrual cycle due to their continuous production. Such fluctuating female hormone levels can change conditions inside the mouth and allow bacterial growth as a result of decreased saliva, such bacteria use the eaten sugar to make acid, that acid can destroy the enamel (the protective coating of teeth) causing tooth decay and many dental problems as dental caries that caused by the progress of carious pathogens and increased de mineralization of tooth. Another problem is gingivitis or bleeding tender gums that are the most common dental problem affecting around $60.0 \%$ to $70.0 \%$ of pregnant women, such condition is common due to decreased immune response, fluctuating hormones and changes in the normal flora. [2-3]

Gingivitis, if untreated, it will progress and cause periodontitis, a condition which is manifested by redness, edema and a higher tendency toward bleeding that causes destruction of periodontal ligaments and bone affecting about $30.0 \%$ of pregnant women causing tooth mobility and loss. The infected periodontium can represent an endocrine like a source of potentially deleterious 
cytokines and lipid mediators which may increase the likelihood of pregnancy complications as preeclampsia and adverse outcomes as preterm delivery of low birth weight babies. It is imperative, therefore, that dentist recognizes, customize and vary periodontal therapy, according to an individual female and the stage of her life cycle. [3-5]

Furthermore, pregnant women often have misconceptions and myths about oral health during pregnancy that prevents them from seeking dental care as poor oral health is normal and accepted during pregnancy or that dental treatment can harm the fetus resulting in neglected oral hygiene. Hence, proper nutrition and healthy lifestyle including good oral hygiene practices play an important role in the general well-being of pregnant women. In addition, women should routinely be kept posted about the maintenance of good oral health care during the whole of their lives as well as during pregnancy that will minimize the risk of pregnancy and adverse outcomes. Nurses are one of the main health care providers of antenatal health care services and play important roles in increasing awareness of oral health and dissemination of information. Furthermore, nurses are in a good position to help deliver key oral health messages to pregnant women. In particular, nurses can provide advice on preventive oral health care, including regular dental visits, and can refer pregnant women to dentists for examinations. [4-7]

\section{AIM OF THE STUDY}

This study aims to enhance pregnant women knowledge about dental care and periodontitis outcomes. This aim was achieved through:

a. Assessing women's knowledge about dental care and periodontitis.

b. Designing and implementing an educational program.

c. Evaluating the effect of an educational program on women's knowledge.

\section{RESEARCH HYPOTHESIS}

Women's knowledge about dental care and periodontitis will enhance after conducting the educational program.

\section{SubJECTS AND Methods}

The methodology followed for achieving this aim was elaborated under the following four main topics namely:

Technical design

Administrative design

Operational design
Statistical design

\subsection{The Technical Design}

The technical design used for the study involved the following items; research design, the setting of the study, the sample of the study and tools for data collection.

\subsubsection{Research design: A quasi-experimental study design}

4.1.2. Setting: The study was conducted at the antenatal care unit in Ain Shams Maternity University Hospital, Cairo, Egypt.

\subsubsection{Subjects}

\subsubsection{Sampling: Convenient sample}

4.1.3.2. Sample Size: The above-mentioned study setting received 300 pregnant women during the six months of data collection period (four months for sample collection and two months for follow up) by using time series analysis.

a. Inclusion criteria: Normal pregnant women in the $1^{\text {st }}, 2^{\text {nd }} \& 3^{\text {rd }}$ trimester with different age group, parity, can read and write were included in the study.

b. Exclusion criteria: All high-risk pregnancies

4.1.3.3. Sample Technique: All available pregnant women fulfilling inclusion criteria that were attending the antenatal care unit at $\mathrm{A}$ in Shams Maternity University Hospital-Cairo, Egypt were included in the study. The sample was collected in the predetermined duration that was six months from $1^{\text {st }}$ July 2018 to $30^{\text {th }}$ December 2018.

\subsubsection{Tools of data collection}

Two tools were adapted by the researchers based on the review of literature considering the aim of the study and the data needed to be collected.

\section{A) A structured-interview-questionnaire includes} 5 parts

i. First part: Concerned with bio-sociodemographic data that covered women age, address, education level, occupation, marital status, residence and social level

ii. Second part: Concerned with obstetrical \& family history taken (gravidity, parity, abortion, stillbirths, low birth weight, preterm labor complications related to previous pregnancy, data about the current pregnancy, etc...).

iii. Third part: Concerned with an assessment of women's knowledge regarding risk factors of periodontitis (bad oral hygiene, bad habits as smoking, bad nutritional habits, medications, economic factors, 
social factors, etc...).

iv. Fourth part: Concerned with the assessment of women's knowledge regarding pregnancy outcome of periodontitis (abortion, bleeding, preterm labor, low birth weight, preeclampsia, etc ....).

v. Fifth part: Concerned with the assessment of women's knowledge regarding dental care (importance, source of information, barriers of irregular teeth brushing, etc....).

Scoring of the questions: The questions were corrected, each correct answer was given a score (2) the wrong answer was given a score (1).

\section{B) An Arabic Educational Booklet}

Developed by the researchers supported by colored illustrated pictures about dental care and periodontitis

\subsection{The Operational Design}

The study to be completed was passed through different phases as follows: Preparatory phase then the pilot study and the fieldwork

\subsubsection{Preparatory phase}

It includes reviewing current and past, national, and international related literature and theoretical knowledge of various aspects of the study using books, articles, internet, periodicals, and magazines to develop tools for data collection related to the aim of the study. The adopted tools were examined by a group of three experts (specialized university professors) in the field of maternity \& gynecological nursing to measure the validity and reliability of tools and the necessary corrections according to their opinions and comments modifications were done.

\subsubsection{Ethical Consideration}

The ethical research considerations in this study include that the research approval was obtained from the Scientific Research Ethical committee in the Faculty of Nursing at Ain Shams University before starting the study. Then, the researcher clarified the objective and aim of the study to the participants included in the study. After that, written consent was obtained from participants after explaining the purpose of the study based on that no harmful methodology was used and that each participant had the right to withdraw from the study at any time. At the same time, all human rights were secured and data as confidential and using coding system form data.

\subsubsection{Pilot Study}

A pilot study was carried out on 30 participants attended the study setting. The pilot study was aimed to test clarity, the arrangement of the items, applicability of the data collection tools and timeconsuming to fill in the tools. After analyzing the results of the pilot study the items were been rearranged and tools modifications were done based on the findings of the pilot study. Some questions were excluded, rephrased and then the final form was developed.

\subsubsection{Field Work}

After approval was taken from the director of the previously mentioned study setting, the researcher attended the antenatal clinics in the study setting for 3 days per week from 9:00 am to 1:00 pm for 6 months from the beginning of July 2018 to the end of December 2018.

The researcher started small educational sessions consisted of 20 groups each group included 15 pregnant women. A pre-test was conducted by distributing the structured questionnaire after sufficient clarification for the participants in each small group. Each group took 30-40 minutes to complete the study tool, after that one teaching session 2 hours, containing interactive group discussion and using power-point presentation, followed by a break, and then closing by an overall summarization. Power-point presentation and booklet are giving for the participant women to be used in a later time and to help in awarding other relative personnel. The content was included well-formed information about the definition, signs and symptoms, causes, risk factors, treatment, adverse effects, preventive measures of periodontitis and dental care importance. The final test was done immediately after administration of the educational session, then after four months of administering the educational session, follow up was done by using the same pretest tool.

\subsection{The Administrative Design}

Official approval to conduct this study was obtained from the Dean of faculty of nursing Ain Shams University. A letter containing the title and aim was directed to the director of the study setting for data collection.

\subsection{Statistical Design}

Recorded data were analyzed using the statistical package for social sciences, version 20.0 (SPSS Inc., Chicago, Illinois, USA). Quantitative data were expressed as mean \pm standard deviation (SD). Qualitative data were expressed as frequency and percentage. The following tests were done: 
- Chi-square $\left(\mathrm{X}^{2}\right)$ test of significance was used in order to compare proportions between qualitative parameters.

- The confidence interval was set to $95 \%$ and the margin of error accepted was set to $5 \%$. So, the $\mathrm{p}$ - value was considered significant as the following:

- P-value $\leq 0.05$ was considered significant.

- P-value $\leq 0.001$ was considered as highly significant.

○ P-value $>0.05$ was considered insignificant.

\section{ReSUlts}

Table (1) shows that the mean age of the studied sample is $26.77 \pm 3.29,56.3 \%$ of the studied sample were a secondary level of education, $(65.0 \%)$ were lived in a rural area and $(89.0 \%)$ were housewives. Concerning their income, $(51.3 \%)$ of them had not enough income. Regarding their marital status (97.8\%) of them was married.

Table (2) illustrates that $70.7 \%$ of the studied sample was in the $3^{\text {rd }}$ pregnancy trimester. Regarding their teeth complications associated with current pregnancy, the chief complaint was bleeding with brushing and spontaneous gingival bleeding $59.0 \%$ \& $14.3 \%$, respectively.

Table (3) reveals that there was a statistically significant difference of the studied women's knowledge about risk factors of periodontitis after the educational session and at follow up time compared to their knowledge before it (Pvalue $<0.001)$.

Figure (1) points out that causes of irregular brushing teeth as mentioned by the studied sample were teeth brushing pain, forgetting teeth brushing times, not get used to teeth brushing in addition to teeth bleeding $(45 \%, 18 \%, 15 \%$ \& $13 \%)$, respectively.

Table (4) demonstrates that there was a statistically significant difference of the studied women's knowledge about the effect of periodontitis on pregnancy outcomes after the educational session and at follow up time compared to their knowledge before it (P-value $<0.001)$.

Table (5) displays that there was a statistically significant difference of the studied women's knowledge about the dental care during pregnancy after the educational session and at follow up time compared to their knowledge before it (P-value <0.001).

Table1. Distribution of the Participants According to their General Characteristics $(N=300)$

\begin{tabular}{|l|c|c|}
\hline Socio-demographic data & No & \% \\
\hline - Age (in years) & \multicolumn{2}{|c|}{} \\
\hline $20-$ & 138 & 33.0 \\
\hline $25-$ & 63 & 46.0 \\
\hline $30-$ & \multicolumn{2}{|c|}{$26.77 \pm 3.29$} \\
\hline Mean \pm SD & 0 & 21.0 \\
\hline -Women's Educational level & 75 & 0.0 \\
\hline Illiteracy & 169 & 56.0 \\
\hline Primary education & 56 & 18.7 \\
\hline Secondary education & & \\
\hline University education & 195 & 65.0 \\
\hline - Residence & 105 & 35.0 \\
\hline Rural & & \\
\hline Urban & 33 & 11.0 \\
\hline - Occupation & 267 & 89.0 \\
\hline Employed & & \\
\hline House wife & 30 & 10.0 \\
\hline - Family Income level & 154 & 51.3 \\
\hline Enough & 116 & 38.7 \\
\hline Not enough & & \\
\hline Barely enough & 293 & 97.7 \\
\hline - Marital status & 7 & 2.3 \\
\hline Married & 0 & 0.0 \\
\hline Widow & & \\
\hline Divorced & & \\
\hline
\end{tabular}


Educational Program to Enhance Pregnant Women's Knowledge about Dental Care and Periodontitis Outcomes

Table2. Distribution of participants according to their current pregnancy $(N=300)$

\begin{tabular}{|c|c|c|}
\hline Current pregnancy & No & $\%$ \\
\hline \multicolumn{3}{|l|}{ Gestational age (in weeks) } \\
\hline $1^{\text {st }}$ trimester & 28 & 9.3 \\
\hline $2^{\text {nd }}$ trimester & 60 & 20.0 \\
\hline $3^{\text {rd }}$ trimester & 212 & 70.7 \\
\hline \multicolumn{3}{|c|}{ Teeth complications associated with current pregnancy } \\
\hline Spontaneous gingival bleeding & 43 & 14.3 \\
\hline Bleeding with brushing & 177 & 59.0 \\
\hline Sensitive gingiva & 30 & 10.0 \\
\hline Pain with brushing & 23 & 7.7 \\
\hline Painful gingiva & 17 & 5.7 \\
\hline Bad breath on the morning & 10 & 3.3 \\
\hline
\end{tabular}

Table3. Distribution of participants regarding their knowledge about periodontitis risk factors $(N=300)$

\begin{tabular}{|c|c|c|c|c|c|c|c|c|c|}
\hline \multirow{2}{*}{\multicolumn{2}{|c|}{ Periodontitis risk factors }} & \multirow{2}{*}{\multicolumn{2}{|c|}{ Pre }} & \multirow{2}{*}{\multicolumn{2}{|c|}{ Post }} & \multirow{2}{*}{\multicolumn{2}{|c|}{ Follow up }} & \multirow{2}{*}{\multicolumn{2}{|c|}{ p-value }} \\
\hline & & & & & & & & & \\
\hline 1-Oral factors & & No. & $\%$ & No. & $\%$ & No. & $\%$ & Pre post & Post \& Follow Up \\
\hline \multirow[t]{2}{*}{ A- Using brushing teeth } & Correct & 69 & 23.0 & 258 & 86.0 & 246 & 82.0 & \multirow{2}{*}{$<0.001 * *$} & \multirow{2}{*}{0.221} \\
\hline & Incorrect & 231 & 77.0 & 42 & 14.0 & 54 & 18.0 & & \\
\hline \multirow{2}{*}{ B- Use of dental floss } & Correct & 27 & 9.0 & 204 & 68.0 & 189 & 63.0 & \multirow{2}{*}{$<0.001 * *$} & \multirow{2}{*}{0.229} \\
\hline & Incorrect & 273 & 91.0 & 96 & 32.0 & 111 & 37.0 & & \\
\hline \multirow{2}{*}{$\begin{array}{l}\text { C-Irregular dentists follow } \\
\text { up visits }\end{array}$} & Correct & 54 & 18.0 & 267 & 89.0 & 261 & 87.0 & \multirow{2}{*}{$<0.001 * *$} & \multirow{2}{*}{0.529} \\
\hline & Incorrect & 246 & 82.0 & 33 & 11.0 & 39 & 13.0 & & \\
\hline \multirow{2}{*}{$\begin{array}{l}\text { D- Effect of pregnancy } \\
\text { hormones }\end{array}$} & Correct & 84 & 28.0 & 264 & 88.0 & 255 & 85.0 & \multirow{2}{*}{$<0.001 * *$} & \multirow{2}{*}{0.339} \\
\hline & Incorrect & 216 & 72.0 & 36 & 12.0 & 45 & 15.0 & & \\
\hline \multicolumn{10}{|l|}{ 2-Behavioral factors } \\
\hline \multicolumn{10}{|l|}{ A- Nutrition \& life Style } \\
\hline \multirow{2}{*}{$\begin{array}{l}\text { 1- Consuming a lot of } \\
\text { drinking beverages and } \\
\text { sweaty food }\end{array}$} & Correct & 60 & 20.0 & 255 & 85.0 & 237 & 79.0 & \multirow[b]{2}{*}{$<0.001 * *$} & \multirow[b]{2}{*}{0.072} \\
\hline & Incorrect & 240 & 80.0 & 45 & 15.0 & 63 & 21.0 & & \\
\hline \multirow{2}{*}{$\begin{array}{l}\text { 2- Craving unusual food that } \\
\text { may harm teeth }\end{array}$} & Correct & 45 & 15.0 & 249 & 83.0 & 234 & 78.0 & \multirow{2}{*}{$<0.001 * *$} & \multirow{2}{*}{0.149} \\
\hline & Incorrect & 255 & 85.0 & 51 & 17.0 & 66 & 22.0 & & \\
\hline 3- Unhealthy diet during & Correct & 96 & 32.0 & 276 & 92.0 & 267 & 89.0 & $0001 * *$ & 0265 \\
\hline pregnancy & Incorrect & 204 & 68.0 & 24 & 8.0 & 33 & 11.0 & 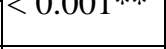 & \\
\hline B-Stress as having familial & Correct & 108 & 36.0 & 246 & 82.0 & 228 & 76.0 & & \\
\hline $\begin{array}{l}\text { or occupational stressors in } \\
\text { the life cannot cope with }\end{array}$ & Incorrect & 192 & 64.0 & 54 & 18.0 & 72 & 24.0 & $<0.001 * *$ & 0.088 \\
\hline & Correct & 68 & 22.7 & 252 & 84.0 & 240 & 80.0 & & \\
\hline & Incorrect & 232 & 77.3 & 48 & 16.0 & 60 & 20.0 & & \\
\hline
\end{tabular}

Using: Chi-square test $\left(x^{2}\right) P$-value $>0.05(N S) * p$-value $<0.05(S) * * p$-value $<0.001$ (HS)

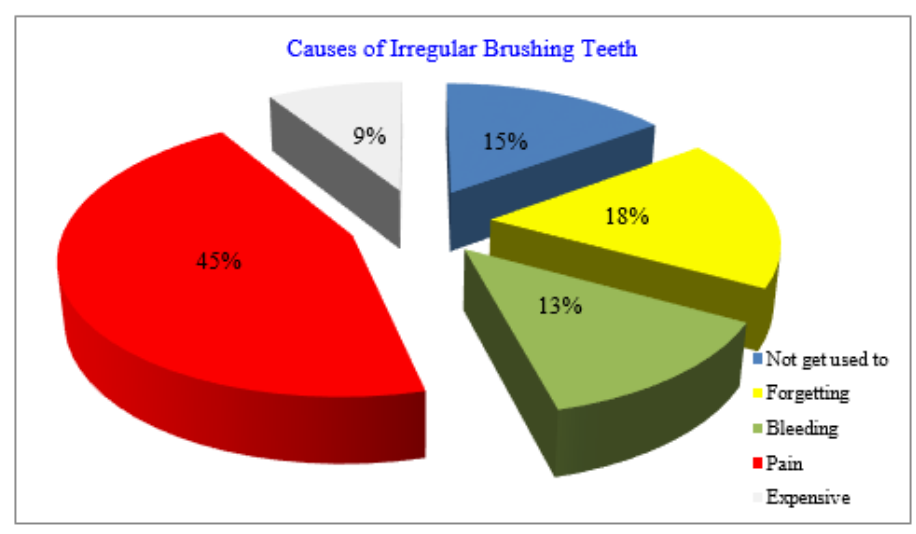

Figure1. Causes of Irregular Brushing Teeth 
Educational Program to Enhance Pregnant Women's Knowledge about Dental Care and Periodontitis Outcomes

Table4. Distribution of participants regarding their knowledge about pregnancy outcomes of periodontitis $(N=300)$.

\begin{tabular}{|c|c|c|c|c|c|c|c|c|c|}
\hline \multirow{2}{*}{\multicolumn{2}{|c|}{$\begin{array}{l}\text { Knowledge about Effect of Perio- } \\
\text { dontitis on Pregnancy Outcomes }\end{array}$}} & \multicolumn{2}{|l|}{ Pre } & \multicolumn{2}{|l|}{ Post } & \multicolumn{2}{|c|}{ Follow up } & \multicolumn{2}{|l|}{ p-value } \\
\hline & & \multirow{2}{*}{ No. } & \multirow{2}{*}{$\%$} & \multirow{2}{*}{ No. } & \multirow{2}{*}{$\%$} & \multirow{2}{*}{ No. } & \multirow[t]{2}{*}{$\%$} & \multirow{2}{*}{ Pre \& post } & \multirow{2}{*}{ Post \& Follow Up } \\
\hline Maternal & & & & & & & & & \\
\hline \multirow{2}{*}{$\begin{array}{l}\text { Systemic diseases (stroke, } \\
\text { diabetes mellitus, myocardial } \\
\text { infarction, atherosclerosis) }\end{array}$} & Correct & 57 & 19.0 & 255 & 85.0 & 240 & 80.0 & \multirow[t]{2}{*}{$<0.001 * *$} & \multirow[t]{2}{*}{0.133} \\
\hline & Incorrect & 243 & 81.0 & 45 & 15.0 & 60 & 20.0 & & \\
\hline \multirow{2}{*}{ Preeclampsia } & Correct & 51 & 17.0 & 261 & 87.0 & 246 & 82.0 & \multirow{2}{*}{$<0.001 * *$} & \multirow{2}{*}{0.114} \\
\hline & Incorrect & 249 & 83.0 & 39 & 13.0 & 54 & 18.0 & & \\
\hline \multirow{2}{*}{ Prolonged labor } & Correct & 69 & 23.0 & 243 & 81.0 & 228 & 76.0 & \multirow{2}{*}{$<0.001 * *$} & \multirow{2}{*}{0.164} \\
\hline & Incorrect & 231 & 77.0 & 57 & 19.0 & 72 & 24.0 & & \\
\hline \multirow{2}{*}{ Post- Partum hemorrhage } & Correct & 36 & 12.0 & 264 & 88.0 & 249 & 83.0 & \multirow{2}{*}{$<0.001 * *$} & \multirow{2}{*}{0.105} \\
\hline & Incorrect & 264 & 88.0 & 36 & 12.0 & 51 & 17.0 & & \\
\hline \multicolumn{10}{|l|}{ Neonatal } \\
\hline \multirow[b]{2}{*}{ Preterm Birth } & Correct & 66 & 22.0 & 246 & 82.0 & 231 & 77.0 & \multirow[b]{2}{*}{$<0.001 * *$} & \multirow[b]{2}{*}{0.157} \\
\hline & Incorrect & 234 & 78.0 & 54 & 18.0 & 69 & 23.0 & & \\
\hline \multirow{2}{*}{ Low Birth Weight } & Correct & 51 & 17.0 & 261 & 87.0 & 246 & 82.0 & \multirow{2}{*}{$<0.001 * *$} & \multirow{2}{*}{0.114} \\
\hline & Incorrect & 249 & 83.0 & 39 & 13.0 & 54 & 18.0 & & \\
\hline Dosniratory dictros & Correct & 45 & 15.0 & 267 & 89.0 & 252 & 84.0 & & 000 \\
\hline Respitatury ustress & Incorrect & 255 & 85.0 & 33 & 11.0 & 48 & 16.0 & -0.001 & ד \\
\hline Neonotol deott & Correct & 54 & 18.0 & 258 & 86.0 & 243 & 81.0 & $<0 \Omega$ & 012 \\
\hline Neorratar deati & Incorrect & 246 & 82.0 & 42 & 14.0 & 57 & 19.0 & $-0.001+2$ & 0.124 \\
\hline Ahortion & Correct & 54 & 18.0 & 258 & 86.0 & 243 & 81.0 & $<0001 * *$ & 0178 \\
\hline AOUItivil & Incorrect & 246 & 82.0 & 42 & 14.0 & 57 & 19.0 & -0.001 & 0.170 \\
\hline Total knowledoe & Correct & 56 & 18.7 & 255 & 85.0 & 240 & 80.0 & $<0001 * *$ & 0133 \\
\hline Dotar nnowica & Incorrect & 244 & 81.3 & 45 & 15.0 & 60 & 20.0 & 0.001 & 0.100 \\
\hline
\end{tabular}

Using: Chi-square test $\left(\mathrm{x}^{2}\right) P$-value $>0.05(N S) * P$-value $<0.05(S) * * P$-value $<0.001$ (HS)

Table5. Distribution of participants regarding their knowledge about dental health care $(N=300)$.

\begin{tabular}{|c|c|c|c|c|c|c|c|c|c|}
\hline \multirow{2}{*}{\multicolumn{2}{|c|}{ Knowledge about dental health care }} & \multicolumn{2}{|l|}{ Pre } & \multicolumn{2}{|l|}{ Post } & \multicolumn{2}{|c|}{ Follow up } & \multicolumn{2}{|l|}{$\mathrm{p}$-value } \\
\hline & & \multirow{2}{*}{\begin{tabular}{|l|} 
No. \\
76 \\
\end{tabular}} & \multirow{2}{*}{\begin{tabular}{|l|}
$\%$ \\
25.3 \\
\end{tabular}} & \multirow{2}{*}{\begin{tabular}{|l|} 
No. \\
284 \\
\end{tabular}} & \multirow{2}{*}{\begin{tabular}{|l|}
$\%$ \\
94.7 \\
\end{tabular}} & \multirow{2}{*}{\begin{tabular}{|l|} 
No. \\
271 \\
\end{tabular}} & \multirow{2}{*}{\begin{tabular}{|l|}
$\%$ \\
90.3 \\
\end{tabular}} & \multirow{3}{*}{\begin{tabular}{l|}
$\begin{array}{l}\text { Pre \& } \\
\text { post }\end{array}$ \\
$<0.001^{* *}$
\end{tabular}} & \multirow{3}{*}{$\begin{array}{c}\text { Post \& Follow Up } \\
0.063\end{array}$} \\
\hline \multirow{2}{*}{$\begin{array}{l}\text { Importance of dental health } \\
\text { care }\end{array}$} & Correct & & & & & & & & \\
\hline & Incorrect & 224 & 74.7 & 16 & 5.3 & 29 & 9.7 & & \\
\hline \multirow{2}{*}{ Brushing teeth frequency } & Correct & 30 & 10.0 & 225 & 75.0 & 208 & 69.3 & \multirow[b]{2}{*}{$<0.001 * *$} & \multirow[b]{2}{*}{0.145} \\
\hline & Incorrect & 270 & 90.0 & 75 & 25.0 & 92 & 30.7 & & \\
\hline \multirow{2}{*}{$\begin{array}{l}\text { Material \& methods of } \\
\text { cleaning teeth }\end{array}$} & Correct & 59 & 19.7 & 294 & 98.0 & 287 & 95.7 & \multirow[b]{2}{*}{$<0.001 * *$} & \multirow[b]{2}{*}{0.162} \\
\hline & Incorrect & 241 & 80.3 & 6 & 2.0 & 13 & 4.3 & & \\
\hline \multirow{2}{*}{ Reasons for visiting dentists } & Correct & 92 & 30.7 & 291 & 97.0 & 281 & 93.7 & \multirow[b]{2}{*}{$<0.001 * *$} & \multirow[b]{2}{*}{0.082} \\
\hline & Incorrect & 208 & 69.3 & 9 & 3.0 & 19 & 6.3 & & \\
\hline \multirow[b]{2}{*}{ Routine dentists visits } & Correct & 66 & 22.0 & 281 & 93.7 & 268 & 89.3 & \multirow[b]{2}{*}{$<0.001 * *$} & \multirow[b]{2}{*}{0.075} \\
\hline & Incorrect & 234 & 78.0 & 19 & 6.3 & 32 & 10.7 & & \\
\hline \multirow{2}{*}{ Total knowledge } & Correct & 65 & 21.7 & 275 & 91.7 & 262 & 87.3 & \multirow{2}{*}{$<0.001 * *$} & \multirow[b]{2}{*}{0.110} \\
\hline & Incorrect & 235 & 78.3 & 25 & 8.3 & 38 & 12.7 & & \\
\hline
\end{tabular}

Using: Chi-square test $\left(x^{2}\right) P$-value $>0.05(N S) * P$-value $<0.05(S) * * P$-value $<0.001$ (HS) 
Figure (2) indicates that the main source of information about dental health care as mentioned by the studied sample were friends and relatives $(31.7 \% \& 15.7)$, respectively.

Figure (3) shows that, there was statistically significant difference between women's knowledge of the pre/post and post/retained regarding total knowledge score (P-value $<0.001)$.

Table (6) shows that there were statistical significant relations between the women's total level of knowledge and their age, women's educational level, residence, occupation and family income, with P-value $<0.05$.

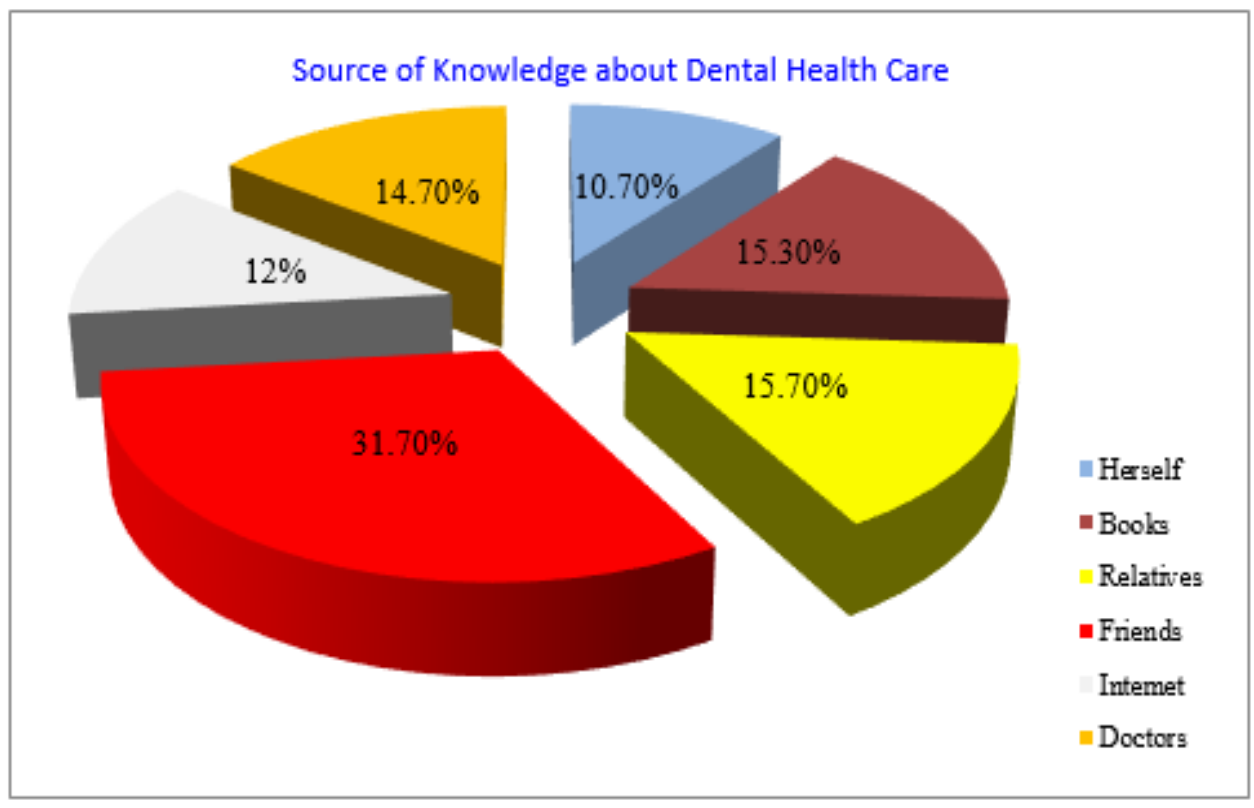

Figure2. Source of women's knowledge about dental health care

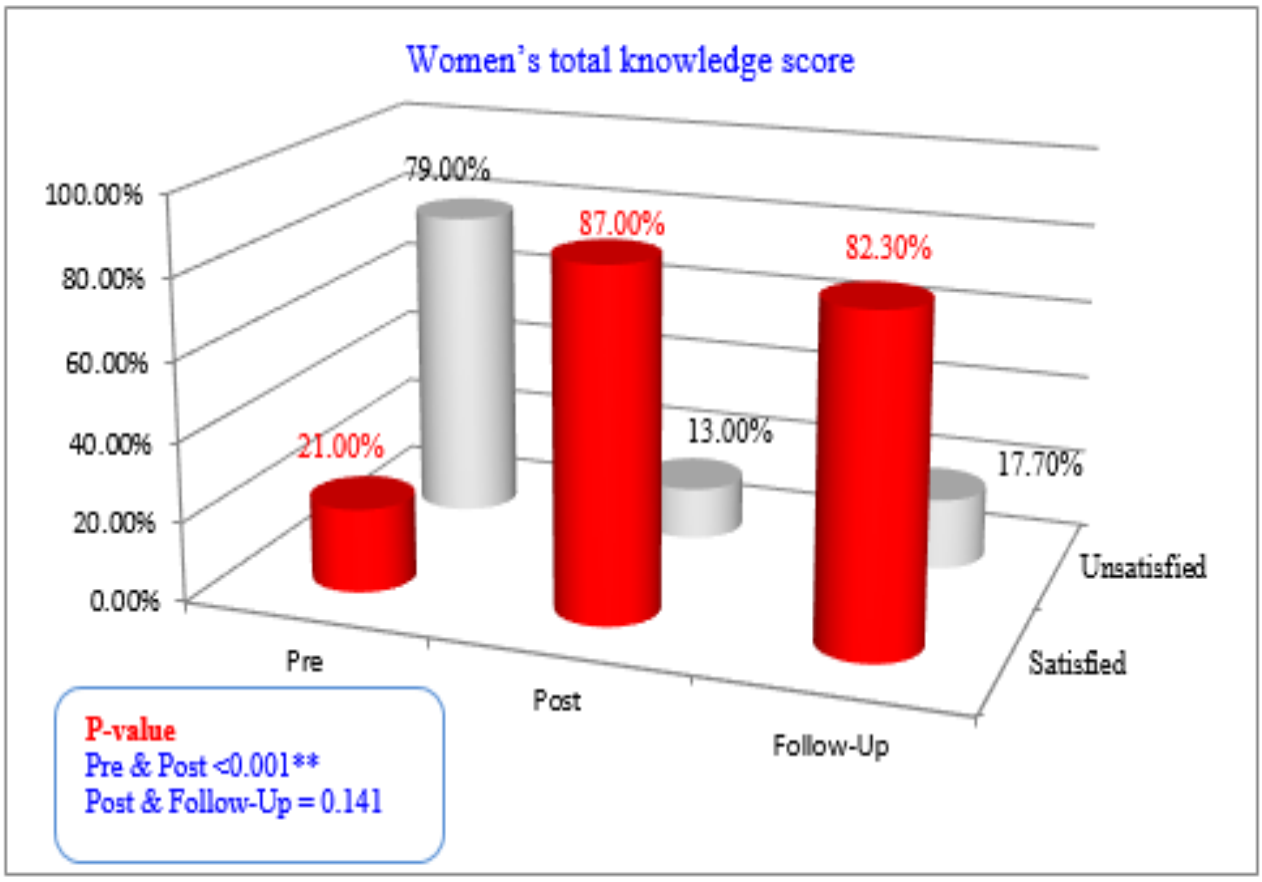

Figure3. Women's total knowledge score

\section{DISCUSSION}

Researches on improving women's knowledge concerning dental health care in Africa are relatively rare due to low prioritization [7].
Different studies show poor maternal oral health and, unfortunately, oral hygiene in pregnant women faces different other barriers to achieve maximum oral health. These barriers include lack 
of knowledge, negative oral health experience and negative attitude of dental staff toward pregnant women. $[8,9,10,13,14]$ Thus, educating pregnant women on oral health can be an effective way of conveying dental health education to the general public, starting at the individual level, then to the family and finally to the community level. $[15,16]$

Hence, the present study aimed to enhance pregnant women's knowledge about dental care and periodontitis outcomes; this aim was significantly achieved because there are statistically significantly improved of women's knowledge post educational session and follow up about dental care and periodontis outcomes compared to pre-education. With respect to the participants women' condition of preinformation, the greater part of participants had poor knowledge and recognition level about periodontitis risk factors, adverse effect of periodontitis pregnancy outcomes, and dental health care issues as importance, frequency of brushing teeth, material used, in addition to dentists' routine follow- up visits. This appears because of the participants' lack of knowledge, different socio-cultural background as well as educational level. Also, Egyptian woman tolerates pain and don't make dental check-up. Post-intervention educational session the majority of the participant women had correct their knowledge. This is maybe due to the utilization of simple and clear language in the educational session, the appropriate teaching method, and audiovisual aids.

This was in agreement with the study done in India which emphasized how periodontitis affects maternal health and pregnancy outcomes stated that there is a need for more forceful awareness session to help spread the message of periodontitis pregnancy adverse effects and importance of oral health hygiene in order to establish proper healthy habits and prevent oral disease [8]. In similar line bringing issues to light was the need for educational programs was identified during the analysis of pregnant women oral health hygiene in Brasil [9] and its association with lifestyle health habits. Similarly, this study was in accordance with the studies done in Sudan (Khartoum), Fayoum (Egypt), Assuit (Egypt) \& Benha (Egypt) [11, 12, 17, 18] on a pregnant reported that oral health knowledge needs to be enhanced and oral health preventive programs should be developed for pregnant women.

Additionally, there's an improvement in follow up knowledge among the participants, this may be due to the presence of hard and soft copy about periodontitis and dental care. The current study findings accounted that the participants had a poor level of knowledge regarding periodontitis risk factors, consequences on pregnancy outcomes in addition to the importance of dental care and related issues. These results were in matching with two studies which declared that lack of attentiveness and understanding the importance of dental care have a harmful impact on maternal \& fetal health. Subsequent to the educational session the majority of the participant's women had knowledgeable about dental care \& periodontitis pregnancy outcomes. $[19,20]$ This could be due to the clarity and consistency of the educational session and proper media used which increased the women's knowledge and recognition about the study subject.

There was an extremely statistically significant improvement in the total score level of knowledge of the participants about periodontitis (definition, manifestation, risk factor, diagnosis, adverse effect, treatment and prevention) in addition to dental care (importance, oral hygiene habits, dentists check-up visits and reasons) after implementing the educational session and in follow up compared to before the educational session. These findings highlighted the willingness of the participant's women to achieve more information about the issue. Findings of the current study showed that the educational session was improving the participants' level of knowledge as revealed in both post and follow up scores. These results hold up the study hypothesis that health education session for pregnant women will improve and get better their level of knowledge about it. 
Educational Program to Enhance Pregnant Women's Knowledge about Dental Care and Periodontitis Outcomes

Table6. Relation between women's total knowledge and their socio-demographic data $(n=300)$

\begin{tabular}{|c|c|c|c|c|c|c|c|c|c|c|c|c|c|}
\hline \multirow{4}{*}{$\begin{array}{l}\text { Socio-demographic } \\
\text { data }\end{array}$} & \multicolumn{13}{|c|}{ Total knowledge } \\
\hline & \multicolumn{4}{|c|}{ Pre } & \multicolumn{4}{|c|}{ Post } & \multirow{2}{*}{\multicolumn{3}{|c|}{$\begin{array}{c}\text { Follow up } \\
\text { Correct } \\
(n=247)\end{array}$}} & & \\
\hline & \multicolumn{2}{|c|}{$\begin{array}{l}\text { Correct } \\
(n=63)\end{array}$} & \multicolumn{2}{|c|}{$\begin{array}{l}\text { Incorrect } \\
(\mathrm{n}=237)\end{array}$} & \multicolumn{2}{|c|}{$\begin{array}{l}\text { Correct } \\
(n=261)\end{array}$} & \multicolumn{2}{|c|}{$\begin{array}{l}\text { Incorrect } \\
(\mathrm{n}=39)\end{array}$} & & & & \multicolumn{2}{|c|}{$\begin{array}{c}\text { Incorrect } \\
(\mathrm{n}=53)\end{array}$} \\
\hline & No. & $\%$ & No. & $\%$ & No. & $\%$ & No. & $\%$ & No. & q & & No. & $\%$ \\
\hline \multicolumn{14}{|l|}{ Age (in years) } \\
\hline $20-$ & 19 & 30.2 & 80 & 33.8 & 95 & 36.4 & 4 & 10.3 & 92 & 37 & & 7 & 13.2 \\
\hline $25-$ & 27 & 42.9 & 111 & 46.8 & 130 & 49.8 & 8 & 20.5 & 127 & 51 & & 11 & 20.8 \\
\hline 30- & 17 & 27.0 & 46 & 19.4 & 36 & 13.8 & 27 & 69.2 & 28 & 11 & & 35 & 66.0 \\
\hline Chi-square test & \multicolumn{4}{|c|}{1.729} & \multicolumn{4}{|c|}{63.013} & \multicolumn{5}{|c|}{78.738} \\
\hline$p$-value & \multicolumn{4}{|c|}{0.422} & \multicolumn{4}{|c|}{$<0.001 * *$} & \multicolumn{5}{|c|}{$<0.001 * *$} \\
\hline \multicolumn{14}{|l|}{\begin{tabular}{|l|}
$\begin{array}{l}\text { Educational } \\
\text { level }\end{array}$ \\
\end{tabular}} \\
\hline Illiteracy & 0 & 0.0 & 0 & 0.0 & 0 & 0.0 & 0 & 0.0 & 0 & 0.0 & 0 & & .0 \\
\hline $\begin{array}{l}\text { Primary } \\
\text { education }\end{array}$ & 13 & 20.6 & 62 & 26.2 & 73 & 28.0 & 2 & 5.1 & 70 & 28.3 & 5 & & .4 \\
\hline Secondary education & 37 & 58.7 & 132 & 55.7 & 160 & 61.3 & 9 & 23.1 & 157 & 63.6 & 12 & & 2.6 \\
\hline University education & 13 & 20.6 & 43 & 18.1 & 28 & 10.7 & 28 & 71.8 & 20 & 8.1 & 36 & & 7.9 \\
\hline Chi-square test & \multicolumn{4}{|c|}{0.855} & \multicolumn{4}{|c|}{83.664} & \multicolumn{5}{|c|}{102.883} \\
\hline$p$-value & \multicolumn{4}{|c|}{0.652} & \multicolumn{4}{|c|}{$<0.001 * *$} & \multicolumn{5}{|c|}{$<0.001 * *$} \\
\hline \multicolumn{14}{|l|}{ Residence } \\
\hline Rural & 34 & 54.0 & 161 & 67.9 & 189 & 72.4 & 6 & 15.4 & 182 & 73.7 & 13 & & 4.5 \\
\hline Urban & 29 & 46.0 & 76 & 32.1 & 72 & 27.6 & 33 & 84.6 & 65 & 26.3 & 40 & & 5.5 \\
\hline Chi-square test & \multicolumn{4}{|c|}{3.674} & & 46.0 & & & & & 4.21 & & \\
\hline$p$-value & & & 55 & & & $<0.00$ & $1 * *$ & & & & $001^{*}$ & & \\
\hline Occupation & & & & & & & & & & & & & \\
\hline Employed & 9 & 14.3 & 24 & 10.1 & 8 & 3.1 & 25 & 64.1 & 5 & 2.0 & 28 & & 2.8 \\
\hline House wife & 54 & 85.7 & 213 & 89.9 & 253 & 96.9 & 14 & 35.9 & 242 & 98.00 & 25 & & 7.2 \\
\hline Chi-square test & & & 69 & & & 122.5 & 61 & & & & 9.92 & & \\
\hline$p$-value & & & 51 & & & $<0.00$ & $1 * *$ & & & & .001 & & \\
\hline $\begin{array}{l}\text { Family Income } \\
\text { level }\end{array}$ & & & & & & & & & & & & & \\
\hline Enough & 11 & 17.5 & 19 & 8.0 & 7 & 2.7 & 23 & 59.0 & 5 & 2.00 & 25 & & 7.2 \\
\hline Not enough & 32 & 50.8 & 122 & 51.5 & 148 & 56.7 & 6 & 15.4 & 145 & 58.7 & 9 & & 7.0 \\
\hline Barely enough & 20 & 31.7 & 96 & 40.5 & 106 & 40.6 & 10 & 25.6 & 97 & 39.3 & 19 & & 5.8 \\
\hline Chi-square test & & & 31 & & & 120.7 & & & & & 3.86 & & \\
\hline$p$-value & & & 66 & & & $<0.00$ & $1 * *$ & & & & .001 & & \\
\hline
\end{tabular}

\section{LiMitATIONS OF THE STUDY}

1. Most of the participants had the myth that dealing medically with oral condition will harm fetus and decide to postpone oral care after delivery.

2. Taking extra time to convince cases about the importance of oral care during pregnancy.

3. The participants were irregular in their follow up session and it was difficult to come in contact with participant through their phone numbers so it was taking extra time for them.

\section{CONClusion}

The majority of the participant's women had poor knowledge level about periodontitis. Designing and an implementing educational program about the studied subject indicated a significant effect in a remarkable rising of the participants' level of knowledge about it.

\section{RECOMMENDATIONS}

1. Awareness educational program about dental care and periodontitis pregnancy outcomes are supposed to be implemented like a component of the services that provided to 
the pregnant women in the antenatal care clinics and should mainly involve women from all residence area.

2. Using a health education campaign during prenatal care, to increase awareness of oral health among pregnant women and improve oral health practice.

3. Nursing programs and curriculum need to change to prepare and train nursing graduates with core competencies of oral health access to care issues as they are the main oral health educators and providers.

\section{REFERENCES}

[1] Onigbinde O, Sorunke M, Braimoh M, Adeniyi A. Periodontal status and some variables among pregnant women in Nigeria tertiary institution. Ann Med Health Sci Res, 2014; 4: 852-757.

[2] Johnson M, George A, Dahlen H, Ajwani S, Bhole S, Blinkhorn A et al. The midwifery initiated oral health-dental service protocol: an intervention to improve oral health outcomes for pregnant women. BMC Oral Health, 2015; 15:2. DOI:10.1186/1472-6831-15-2

[3] Gambhir R, Nirola A, Gupta T, Sekhon T, Anand S. Oral health knowledge and awareness among pregnant women in India: A systematic review. J Indian Soc Periodontol, 2015; 6(19): 612-617.

[4] Bahri N, Tohidinik HR, Bahri N, Iliati HR, Moshki M, Darabi F. Educational intervention to improve oral health beliefs and behaviors during pregnancy: a randomized-controlled trial. J Egypt Public Health Assoc., 2015; 90(2): 41-45.

[5] Vamos C, Thompson E, Avendano M, Daley E, Quinonez R, Boggess K. Oral health promotion interventions during pregnancy: A systematic review. Community Dent Oral Epidemiol, 2015; 43(5): 385-396.

[6] Naseem M., Khurshid Z., Ali, Niazi F., Zohaib S., and Sohail M. Oral health challenges in pregnant women: Recommendations for dental care professionals, The Saudi Journal for Dental Research, 2016; 7: 138-146.

[7] Hartnett E, Haber J, Krainovich-Miller B, Bella A, Vasilyeva, A, Lange Kessler J. Oral health in pregnancy. J Obstet Gynecol Neonatal Nurs., 2016; 45(4): 565-573. DOI:10.1016/j.jogn.2016

[8] Nagi R, Sahu Sh, Rakesh Nagaraju R. Oral health, nutritional knowledge, and practices among pregnant women and their awareness relating to adverse pregnancy outcomes, 2016, 28(4): 396-402. DOI: 10.4103/jiaomr. JIAOMR _246_15.http://www.jiaomr.in/article.asp?issn= 09721363 ; year $=2016$; volume $=28$; issue $=4$; spag $\mathrm{e}=396$; page $=402 ;$ aulast $=\mathrm{Na}$.
[9] Luciana Luz Araújo de SOUSA, Adriana CAGNANI, Andréia Moreira de Souza BARROS, Luciane ZANIN \& Flávia Martão FLÓRIO: Pregnant women's oral health: knowledge, practices and their relationship with periodontal disease. RGO, Rev. Gaúch. Odontol., 2016; 64 (2), http://dx.doi.org/ 10.15 90/1981- 863720160002000053036.

[10] Ramamurthy J, Irfana F. Assessment of knowledge and awareness about periodontal oral health among pregnant women- a questionnaire study, Int J Cur Res Rev.2017;9(1):9-12.

[11] Ibrahim H, Mudawi A, Ghandour I. Oral health status, knowledge, attitudes and practice among pregnant women attending Omdurman maternity hospital, Sudan. East Mediterr Health J., 2017; 22(11): 802-809

[12] Nagwa R., Magda A. Fawaz, D., Nadia B. Pregnant Women Beliefs on the Impact of Oral/Dental Health on Pregnancy Outcomes in El- Fayoum, Egypt. Med. J. Cairo Univ., 2017; 85(7): 2821-2829. www.medicaljournal of cairo university.net

[13] R. Priya Shanthini, Bharath Kumar Garla, R. Muthu Karuppaiah and M. Taranath: Effectiveness of Anticipatory Guidance on the Knowledge and Attitude of Pregnant Women Attending Government Hospital, Thirumangalam, Madurai. Journal of Advanced Oral Research 8(1 \& 2) 8-13 @ 2017 Academy of Advanced Dental Research SAGE Publications sagepub.in/home. nav DOI: 10.1177/2229411217729100 http://journals. sagepub.com/home/aad

[14] Azodo CC, and Omuemu VO. (2017). Oral health in pregnancy: Self-reported impact of exposure to oral health information. J Clin Sci; 14: 1191-25.

[15] Chawla RM, Shetiya SH, Agarwal DR, Mitra P, Bomble NA, and Narayana DS. (2017). Knowledge, attitude, and practice of pregnant women regarding oral health status and treatment needs following oral health education in Pune District of Maharashtra: A Longitudinal hospital-based study. J Contemp Dent Pract; 18(5): 371-377.

[16] Hein C, Williams RC. The impact of oral health on general health: Educating professionals and patients. Current Oral Health Reports. 2017; 4 (1): 8-13.DOI:10.1007/s40496-017-0124 -4

[17] Shimaa Abdelrahim Khalaf, Safaa Rabea Osman, Ahmed M. Abbas \& Taghreed m AbdulAziz M. Ismail: Knowledge, attitude and practice of oral healthcare among pregnant women in Assiut, Egypt. International Journal of Community Medicine and Public Health Khalaf SA et al. Int J Community Med Public Health, 2018; 5(3):890-900 http://www. ijcmph.com 
[18] EL Sayed E., Said S. Effect of Nursing Intervention on Oral Health Knowledge, Attitude, and Health Behaviors among Pregnant Women. American Journal of Nursing Research, 2018; 6(3), 94-104. DOI: 10.12691/ ajnr-6-3-3.

[19] Poshtamsary S., Sigaroudi A., Farmanbar R., Radafshar G., Roushan Z. The Effect of Educational Program on Dental Plaque and Caring Performance of Pregnant Mothers.
Cjhr.gums.ac.ir Caspian J Health Res., 2018; 3(2): 58-63. doi: 10.29252/cjhr.3.2.58

[20] Marla V., Srii R., Roy D., \& Ajmera H. The Importance of Oral Health during Pregnancy: A review. MedicalExpress (São Paulo, online), 2018; 5. http://dx.doi.org/10.5935/medical expr ess.2018.mr.002

Citation: Walaa Fathy Mohamed, Hanan Elzeblawy Hassan, Educational Program to Enhance Pregnant Women's Knowledge about Dental Care and Periodontitis Outcomes. ARC Journal of Nursing and Healthcare. 2019; 5(3):23-33. doi: dx.doi.org/ 10.20431/2455-4324.0503004.

Copyright: (c) 2019 Authors. This is an open-access article distributed under the terms of the Creative Commons Attribution License, which permits unrestricted use, distribution, and reproduction in any medium, provided the original author and source are credited. 